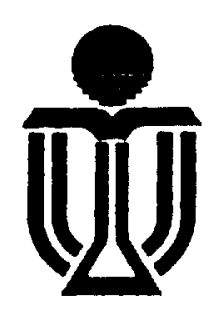

Division of Social Science

The Hong Kong University of Science and Technology

Working Papers in the Social Sciences, No. 17

\title{
Social Identification in a Political Transition: The Role of Implicit Beliefs
}

by

Ying-yi Hong Chi-yue Chiu

Division of Social Science Hong Kong University of Science and Technology Clear Water Bay Kowloon, Hong Kong
Department of Psychology The University of Hong Kong Knowles Building Pokfulam Road Hong Kong

12 June 1997 
Running head: SOCIAL IDENTIFICATION IN POLITICAL TRANSITION

\author{
Social Identification in a Political Transition: \\ The Role of Implicit Beliefs \\ Ying-yi Hong ${ }^{1} \quad$ Chi-yue Chiu ${ }^{2}$
}

1 Division of Social Science,

The Hong Kong University of Science and Technology

2 Department of Psychology,

The University of Hong Kong

During preparation of this manuscript, the authors received support from a grant (HKUST551/95H) from the Research Grants Council, Hong Kong. We thank Hoying $\mathrm{Fu}, \mathrm{Kam}$-ling Lee, Mary Lo and Grace Yeung for their assistance in data processing. All correspondence should be addressed to Ying-yi Hong, Division of Social Science, The Hong Kong University of Science and Technology, Clear Water Bay, Hong Kong. Email: sohong@usthk.ust.hk, or to Chi-yue Chiu, Department of Psychology, The University of Hong Kong, Pokfulam Road, Hong Kong. Email: cychiu@hkusua.hku.hk

Keywords: Implicit Theories, Social Identification

Paper presented in the "Global Perspectives on 'Hot' Topics: Culture's Influence on Human Motivation" Symposium at the 1997 Annual Convention of the American Psychological Society, Washington, DC: May, 1997, and at the International Conference on the Transition to HKSARPRC, Hong Kong: 7-9 July, 1997. 


\begin{abstract}
The social identification model posits that social identification is a social psychological expression of the universal needs for connectedness and differentiation. We propose that compared to individuals who believe that the social world is malleable, individuals who believe that the social world is a fixed reality may feel more strongly that people should harmonize the self with, rather than differentiate it from, the fixed social world. Individuals who hold a fixed world view may thus have a relatively stronger connectedness motivation and a relatively weaker differentiation motivation. This proposal was tested in an experimental study (Study 1) and a longitudinal study (Stıdy 2), both set in the context of the 1997 political transition in Hong Kong, in which Hong Kong people faced the social identification issue of whether to identify themselves with the more inclusive Chinese group or to affirm their distinctive Hong Konger identity. The results supported our proposal and were discussed in terms of their implications for several theoretical models of social identification an 1 for the social identification processes in transitional Hong Kong.
\end{abstract}


Social identification in political transition -3

\section{Social Identification in a Political Transition:}

\section{The Role of Implicit Beliefs}

On July 1, 1997, after almost 155 years of British colonial rule, the sovereignty of Hong Kong was turned over to the People's Republic of China (PRC). On the same day, Hong Kong people became members of the Hong Kong Special Administrative Region of the PRC and were thereby politically assimilated into China. The adoption of a new regional emblem and the issue of the Hong Kong Special Administrative Region Passport, toget ner with many other social political changes, all serve to remind Hong Kong peofle of their new group membership. Increasingly, Hong Kong people may need to change their frame of reference for social comparison, negotiate their social identities and reconsider their customary ways of interacting with Chinese Mainlanders (cf. Deaux, 1993). To most Hong Kong people, the ideal post-1997 political scenario would be "One country, two systems." However, the question is what Hong Kong people want to identify themselves with. Do they want to identify theinselves with the country, or with do they want to identify themselves with Hong Kong's distinctive system?

It is within this socio-historical context that we tested an important theoretical extension of the social categorization model (Erewer, 1991, 1993). Specially, using the social political situation in transitional Hong Kong as a case in point, we examined in two studies how social identification and intergroup relations are related to an individual's socially constructed world view.

\section{The Social Categorization Model}

Within the social categorization model (Frewer, 1991, 1993), social identification is a social psychological expression of the universal needs to seek social connectedness and to differentiate the self from others. As connectedness and differentiation are opposing social motivations, individuals searching for social identities may feel the psychological tension generated by the two motivational forces. To reconcile these conflicting forces, these individuals may try to find an identity that would optimize the likelihood of f llfilling both needs. As such, an 
individual's self-chosen social identity at a given moment is a reflection of what the individual construes at that moment to be the self-identity that could simultaneously maximize the likelihood of achieving connectedness and distinctiveness. In other words, the identity needs to be perceived by the individual to be at a level of inclusiveness-distinctiveness that would give the individual a sense of belongingness and at the same time allow the individual to be recognized by the self and others as a distinctive person.

Furthermore, the specific social identity one will choose depends primarily on the relative strength of the connectedness and differentiation motivations. For example, to most ethnic Chinese in Hong Kong, "Chinese" is a superordinate identity encompassing such regional subtypes as "Hong Kong Chinese" or "mainland Chinese" Hong Kong people who have relatively strong connectedness motivation may identify themselves with the more inclusive Chinese group, whereas those who want to maintain greater distinctiveness may identify themselves with the more distinctive "Hong Konger" subgroup. Consistent with this assumption, there is evidence that Hong Kong people who identify themselves as "Chinese" want to feel more assimilated with other Chinese (e.g., Mainland Chinese), whereas those who identify themselves as "Hong Kongers" or "Jong Kong Chinese" want to distinguish themselves from Mainland Chinese (The Hong Kong Transition Project, 1995, cited in Hong \& Chiu, 1995).

The relative strength of the connectedness and differentiation motivations depends among other factors on the temporary and chronic accessibility of the two motivations. Brewer and her associates (seє Brewer, 1997) have demonstrated the role of temporary accessibility of the needs :or differentiation and connectedness in social identification. For example, their research showed that an experimentally induced need for differentiation increased the importance of group memberships in both distinctive subgroups and superordinate groups. However, the magnitude of increase was greater for memberships in distinctive subgroups than for memberships in inclusive, superordinate groups. 
The Role of Socially Constructed World View

The social categorization model also recognizes the importance of culturally constructed and chronically accessible individual beliefs in the social identification processes. Such beliefs are assumed to affect social identification through their impact on the relative strength of the connectedness and differentiation motivations. As Brewer (1991) posits, "For any individual, the relative strength of the two needs is determined by cultural norms, and individual socialization, and recent experience" (p. 478). This assumption is theoretically important as it provides for the social identification processes a possible interface between the universal needs for connectedness and differentiation on one hand, and the social construction of selfhood and the social reality on the other.

Following this assumption, a theoretical extension of the social categorization can be made by relating the connectedness and differentiation motivations to the independent versus interdependent self constructions (Markus \& Kitayama, 1991; Shweder \& Miller, 1985). Many researchers have noted that different cultures have markedly different construals of the self (Markus \& Kitayama, 1991; Triandis, 1989; Triandis, et al., 1988). Self-construals in many A sian societies tend to emphasize the fundamental connectedness of individuals to each other and the primary importance of harmonizing the self with the external world. In this conception, the individual is expected to accept the social world as a fixed reality, which shapes and governs the individual's cognitions, emotional expression and social action (Miller, 1984; Morris \& Peng, 1994).

By contrast, many American and Europezn societies tend to emphasize a highly individuated conception of the self. Individuals are expected to express their individuality often by displaying a unique conf guration of relatively stable internal attributes. Social actions are expected to be behavioral signatures of the individual's internal qualities (Miller, 1984; Morris \& Peng, 994). In addition, the world and its institutions are expected to be constructed or modified to allow free expression of individuality (Chiu, Dweck, Fu, \& Tong, in press). 
There are clear implications of the ditferent conceptions of selfhood for the connectedness and differentiation motivatic ns. As illustrated in Figure 1, in a society that emphasizes the integration of the self into the collective, the need for connectedness may on average be stronger than the need for differentiation, whereas in a society where a highly individuated conception of the self is emphasized, the reverse may be true (Brewer, 1991). Furthermore, according to the social categorization model, compared to people in societies that emphasize an independent conception of the self, people in societies that emphasize an interdependent conception of the self should rate memberships in more inclusive groups as more important and membershifs in more distinctive subgroups as less important. Cross-cultural research on the spontaneous self-concept (Cousins, 1989; Rhee, Uleman, Lee, \& Roman, 1995) has provided strong support for this latter prediction.

Insert Figure 1 here

As noted, a connected, interdependent conception of the self assumes a relatively nonmalleable social world that shapes and governs individual actions, whereas an independent, differentiated conception of the self assumes a social world that can be changed to allow free expression of individual qualities. Consistent with this view, Chiu, et al. (in press) found that compared to their American counterparts, Hong Kong college students, in line with their interdependent self-construals, believe much more strongly in a fixed social reality, i.e., they believe more strongly that the world and its social institutions cannot be changed much. As self-construal is systematically related to an individual's mplicit belief about the fixedness or malleability of the world, we expect that such implicit beliefs would predict an individual's social identification and its underlying social motivations. Specifically, a fixed view of the social world may be associated with a stronger motivation to harmonize the self with the fixed reality, as expressed in a greater tendency to seek 
connectedness with the more inclusive group. By contrast, a malleable view of the social world, via its association with construals of an independent self, may predict a stronger differentiation motivation, which may be expressed in terms of stronger identification with distinctive groups. In the two studies reported in the present article, we tested this prediction within the context of social identification in transitional Hong Kong. Should this prediction be borne out, it would suggest social identification is also an outcome of social constructive processes, since the expression of the basic social motivations underlying social identification is also constrained by the way an individual constructs, the social reality.

The Context of Social Identification in Transitional Hong Kong Despite their shared ethnicity. Hong Kong people may be regarded as a social group that is distinct from Chinese Mainlander:. Although over $95 \%$ of the some six million Hong Kong residents are ethnic Chinese:, Hong Kong had been a Britishadministered territory since 1842. Most Hong Kong Chinese speak Cantonese, a Chinese dialect, as their mother tongue. In add tion, in about $80 \%$ of the secondary schools, English, not Chinese, is officially the main medium of instruction (Young, Giles \& Pierson, 1986). In contrast, since 1949, mainland China has been a socialist country, and Putonghua is her official language.

The two studies reported in the present article were conducted between September, 1994 and March, 1997. During this ransition period, Hong Kong people increasingly became more aware of a new basis for social comparison resulting from the political changes. In late 1996 and early 1997, the "identity crisis" surfaced as the one of the most frequently discussed topics in the news media in Hong Kong. Interestingly, the crisis revolved around the question of connectedness versus differentiation, i.e., should Hong Kong people be assimilated into the more inclusive "Chinese" group, or should they affirm and favisably evaluate a distinctive Hong Kong identity? During this period, numerous attempts were made from various sectors of the Hong Kong society to strengthen Hong Kong people's identification 
with China. Such efforts were however matched by equally enthusiastic attempts to bolster Hong Kong people's pride in a local Hong Kong identity.

Study 1 was conducted in September, 1994, almost three years before the day of the handover. In this study, we assessed college students' implicit beliefs about the fixedness or malleability of the world. Then, we primed half of the participants with transition-related materials and half with transition-unrelated materials. Subsequent to the priming task, all participants responded to a measure of intergroup biases. Study 2 was a two-wave: longitudinal study, conducted in September 1996 (Wave 1) and March 1997 (Wave 2). In Study 2, social identification was assessed through participants' attitudes towards English and Putonghua learning. In both studies, we predicted that those who believed in a fixed world would display a stronger connectedness and a weaker differentiation intergroup tendency when the transition was made sal ent, i.e., when primed with transitionrelated materials (Study 1) or when the day of the handover (July 1, 1997) approached (Wave 2 vs Wave 1 in Study 2). We also predicted that those who believed in a malleable world would display a weaker connectedness and a stronger differentiation intergroup tendency when the transition was made salient.

\section{Study 1 Method}

\section{Participants.}

The participants were 253 university freshmen (125 females, 134 males) from the Hong Kong University of Science and Technology, with an average age of 19.22 $(\underline{\mathrm{SD}}=85)$.

\section{Measures of Implicit Beliefs}

Implicit beliefs about the fixedness or malleability of the world were assessed by an implicit belief measure developed by Chiu et al. (in press). It consists of statements such as "Some societal trends may dominate for a while, but the fundamental nature of our world is something that cannot be changed," and "Though we can change some phenomena, it is unlikely we can alter the core 
dispositions of our world." Respondents who consistently agree with these statements believe that the world and its existing social institutions are fixed and are labeled fixed theorists. Those who consistently disagree with these statements believe that the world and its existing social institutions are not fixed and are labeled malleable theorists.

Extensive reliability information of the rneasure was reported in Chiu et al. (in press) and Dweck, Chiu, and Hong (1995). The: test-retest reliability for a two-week interval for the measure is .79 . The internal relability of the measure in the present study was .88 . The measure predicts theoretically meaningful clusters of moral beliefs and reactions to rule violations (Chiu, et al., in press). For example, fixed theorists tend to see duties and obligations as the fundamental bases for judging the moral correctness of social actions, whereas malleable theorists tend to see abstract ethical principles (e.g., human liberty) as the fundamental bases for making moral judgments. The implicit theories measure does not correlate with standard measures of self-presentational concerns (the Faulhus, 1984, Social Desirability Scale, or the Synder, 1974, Self-Monitoring Scale), intellectual abilities (SAT scores, or the Bennett et al., 1965, Academic Promise Test), self-esteem (the Coopersmith, 1967, Self-Esteem Inventory), or political attitudes (the Kerlinger, 1984, conservatism and liberalism scales).

In our study, research participants wert classified as fixed theorists or malleable theorists based on their scores on the malleability belief measure. The possible scores of the measure range from 1 to 6 , with a higher score indicating a stronger endorsement of the malleable theory. Participants who scored above 3.50 (the midpoint) on the scale were classified as Inalleable theorists, and those who scored below 3.50 were classified as fixed thec rists.

\section{The Priming Task}

After the participants had completed the implicit belief measure, to assess the impact of the political transition on the participants' intergroup orientations, half of the participants were cued with three 1997-related pictures in an allegedly unrelated 
study on perceptions of graphic designs, and the remaining half were cued with three 1997-unrelated pictures. Figure 2 shows one of the 1997-related pictures and and one of the 1997-unrelated pictures. The three cueing pictures in each condition were mixed with twelve neutral, filler pictures, and the participants were asked to judge the artistic appeal of each of the 15 (3 cueing and 12 filler) pictures on a 9-point scale (from $1=$ "not at all aesthetically pleasing" to 9 "very aesthetically pleasing"). According to the knowledge accessibility theory (e g., Higgins, 1990), cueing participants with 1997-related pictures should make the 1997 issue more cognitively salient than cueing participants with the 1997-unrelated pictures.

Insert Figure 2 here

\section{Measure of Intergroup Bias}

Previous research has shown that people who seek for positive differentiation of their group are likely to display ingroup favoritism and outgroup discrimination (see Tajfel, 1982). For example, when a Ho.ng Kong person violated a rule, participants who wanted to maintain a distinctive Hong Konger identity might exonerate the transgressor and moderate their negative evaluation of the transgressor. However, when a Chinese Mainlander violated a rule, they might make harsher judgments of the transgresscrr. In contrast, for participants who wanted to be assimilated into a more inclusive Chinese group, whether the transgressor was a Hong Kong person or a Chinese Mainlander should not affect their judgment, as both Hong Kong peoplt: and Chinese Mainlanders belong to the more inclusive group. Accordingly, the participants' assimilationist and divergent intergroup responses might be reflected in their judgments of a Hong Kong versus Mainland transgressor.

Thus, after the priming task, we asked participants to read a fictitious news report allegedly taken from a local newspaper and then make a number of judgments. The news report described an industrial accident which was alleged to 
have happened in an electronic watch assembly plant in an industrial complex in Kowloon Bay, Hong Kong. On the day of the incident, a foreman, due to his negligence, did not install the safety cover on the machine properly. The safety cover fell off when the machine was being operiated, and two of the machine operator's fingers were severed by the machine. Half of the participants, randomly selected, were told that the foreman was a local Hong Kong person, and the remaining half were told the foreman was hired from mainland China.

In short, the present experiment used a 2 (Implicit Belief: fixed or malleable) $X$ 2 (Foreman Identity: Hong Kong person or Maidander) X 2 (Cue: 1997-related or 1997-unrelated cueing) between-subject design.

\section{Dependent Measures}

After reading the scenario, all the participants were asked to judge how unfair it would be if the foreman was not punished on a 9-point scale that ranged from 1 ("very unfair") to 9 ("very fair"). They also judged the foreman's morality on a 9point scale that ranged from 1 ("very moral") to 9 ("very immoral"). These judgments formed the dependent measures in the present study.

Our prediction was that, when the 1997 issue was made salient by experimental cueing, fixed theorists, who accepted the world and its social institutions as fixed might also have a stronger connectedness motivation. Accordingly, they might display weaker ingrou p favoritism toward the Hong Kong foreman and weaker outgroup discrimination a gainst the Mainland foreman in their judgments in the 1997-related priming condition than in the 1997-unrelated priming condition.

By contrast, for malleable theorists, who believed that the world and its social institutions could be changed, wher the 1997 is sue was made salient, their differentiation motivation might get stronger, i e., they might have a greater tendency to affirm the desirability of their Hong Kong identity and to distinguish themselves from the Mainlanders. They might thus display stronger ingroup 
favoritism and outgroup discrimination in their judgments in the 1997-related cueing condition than in the 1997-unrelatec cueing condition.

\section{$\underline{\text { Resu. Its }}$}

As in Chiu et al. (in press), fixed theorists $(\underline{N}=174)$ outnumbered malleable theorists $(\underline{N}=79)$ by a wide margin in the present sample. In comparable American samples, the ratio of fixed theorists to malleable theorists was 1.09 to 1 (Chiu et al., in press). This finding is consistent with our assumption that in societies that emphasize a connected, interdependent sense of the self, the social world tends to be construed as a relatively nonmalleable real ty.

In general, the results of the experim ent supported our predictions. A threeway ANOVA was performed on the retributive fairness judgment. The only significant effect was the predicted three-way interaction, $\underline{E}(1,245)=5.53, \underline{p}<.05$, $\underline{\mathrm{MS}} \underline{\underline{e}}=3.24$. As shown in Figure 3, when cued with 1997-unrelated pictures, malleable theorists' retributive fairness judgments were in favor of the Mainland foreman. They thought it would be more unfair if the Hong Kong foreman was not punished than if the Mainland foreman was not punished $(\underline{M}=7.40$ for the Hong Kong foreman and 6.87 for the Mainland foreman), although the difference was not reliable, $\underline{\mathrm{F}}(1,41)=.83$, ns. However, as expected, when cued with the transitionrelated pictures, there was a trend for their judgments toward the Hong Kong foreman to become more lenient $(\underline{M}=7.40$ in the 1997 -unrelated cueing condition and 6.33 in the 1997-related cueing condition), $\mathrm{g}(1,36)=3.70, \mathrm{p}=.06$.

Fixed theorists displayed the oppos te pattern. When cued with 1997unrelated pictures, they were harsher toward the foreman if the foreman was hired from the Mainland $(\underline{M}=7.17)$ than if the foreman was a local Hong Kong person $(\underline{\mathrm{M}}=6.26), \underline{\mathrm{F}}(1,78)=4.84, \mathrm{p}<.05$. However, when the political transition was made cognitively salient by the 1997-related cues, there was a trend for them to become more lenient towards the Mainland forem $a n(\underline{M}=7.17$ in the 1997-unrelated cueing condition and 6.68 in the 1997-related cueing condition), $\mathrm{F}(1,87)=2.87, \mathrm{p}=.09$. 
Insert Figures 3 and 4 here

It is worth noting that when the 1997 issue was not made salient, malleable theorists did not display ingroup favoritism or outgroup discrimination. In fact, their judgments in the 1997-unrelated cueing condition were in favor of the Mainland foreman, although the difference was not significant. In contrast, fixed theorists' judgments were in favor of the Hong Kong foreman in the 1997-unrelated cueing condition. This finding is consistent with previous research which showed that, malleable theorists favor a probabilistic view of social causation more than do fixed theorists, i.e., malleable theorists tend to focus more on situational and psychological processes that mediate wrongdoing (Chiu, Hong, \& Dweck, in press; Hong, Chiu, Dweck, \& Sacks, 1997; see also Drveck, Hong, \& Chiu, 1993; Dweck et al., 1995). Thus, they might exonerate the Maivland transgressor if they thought that he did not know the rules for industrial safety in Hong Kong, or that he was adapting to a new environment. Despite that, when the 1997 issue was made salient (when the social identification issue was broug, ht out in front), malleable theorists displayed a more divergent judgment pattern, whereas fixed theorists displayed a more assimilationist pattern.

The results from the judgment of the foreman's morality showed a similar pattern. A three-way ANOVA was performed. Again, only the three-way interaction was significant, $\underline{F}(1,245)=4.68, \underline{p}<.05, \underline{\mathrm{MS}} \underline{\underline{e}}=1.39$. As shown in Figure 4, when cued with 1997-unrelated pictures, malleable theorists were more lenient towards the Mainland foreman $(\underline{M}=6.09)$ than the Hong Kong foreman $(\underline{M}=6.45)$, although the difference again was not significant, $E(1,41)=0.92$, ns. When cued with 1997-related pictures, malleable theorists beca ne more lenient toward the Hong Kong foreman than the Mainland foreman, $\underline{F}(:, 34)=6.24, \underline{p}<.05$. They now judged the Hong Kong foreman $(\underline{M}=5.50)$ as less immoral than the Mainland foreman $(\underline{M}=6.50)$. 
In contrast, when cued with 1997-unrelated pictures, there was a trend for the fixed theorists to be more lenient towards the Hong Kong foreman ( $M=5.77)$ than the Mainland foreman $(\underline{M}=6.24), \underline{F}(1,78)=3.64, \underline{p}=.06$. However, when cued with 1997 related pictures, fixed theorists did not judge the Hong Kong foreman ( $\underline{M}=5.89)$ to be less immoral than the Mainland foreman $(\underline{M}=6.14), \underline{F}(1,92)=1.06$, ns.

Taken collectively, the findings from this study showed that when the political transition was made salient by priming, Hong Kong people holding a malleable view of the world and its social institution shifted toward a more divergent intergroup orientation in their social judgments, whereas Hong Kong people holding a nonmalleable view of the world shifted toward a more assimilationist orientation. Should this be case, we would expect malleable theorists to display increasingly stronger divergent intergroup attitudes and fixed theorists to display increasingly stronger assimilationist intergroup attitudes as the day of the political handover approached. This expectation was tested in Study 2.

Study 2

\section{Participants}

The participants were 196 college students (113 males, 83 females) from two local universities in Hong Kong. Their average age was $19.77(\underline{\mathrm{SD}}=1.32)$ at Wave 1. They were paid 50 Hong Kong dollars (US\$ 6.40) and 55 Hong Kong dollars (US\$7.05) for their participation in Wave 1 and Wave 2, respectively. None of them had taken part in Study 1. Wave 1 was conducted in September, 1996, about 9 months before the handover, and Wave 2 was conducted in March 1997, just about 100 days before the handover. We expected the identity issues arising from the transition to be more salient in the second rvave than in the first wave.

\section{Measures}

The participants' implicit beliefs abcut the fixedness or malleability of the world were assessed in Wave 1 using the same implicit theory measure used in Study 1. To assess assimilationist and divergent intergroup attitudes, we asked participants in both waves (a) the age at which Hong Kong children should start to 
learn English, and (b) the age at which Hong Kong children should start to learn Putonghua. ${ }^{1}$ We used these measures because previous studies revealed that language is probably the most important marker of social identity (see Krauss \& Chiu, in press). Moreover, as noted, due to the long British rule, about $80 \%$ of the secondary schools still use English, not Chinese, as the main medium of instruction. Although Putonghua is China's official language, in daily communication, most Hong Kong Chinese speak Cantonese, a Chinese dialect. During the transition period, in anticipation of more frequent interastions with Chinese Mainlanders, many Hong Kong people learned Putonghua and Putonghua was introduced as a compulsory subject in some secondary schools. Meanwhile, many schools, including some universities in Hong Kong, insist on using English as the official medium of instruction, in order to maintain a "superior" international academic standard that sets Hong Kong apart from Mai:land China. Interestingly, the native language of over $90 \%$ of the population in Hong Kong was neither English nor Putonghua. Thus, a preference to start learning Putonghua early in life might reflect an assimilationist intergroup attitude, whereas a preference to start learning English early in life might reflect a more divergent intergroup attitude.

We predicted that as the day of the handover approached, fixed theorists would display increasingly more assimilationst language attitudes by recommending a younger age for children in Hong Kong to start to learn Putonghua and by recommending an older age to start to learn English. Malleable theorists should display increasingly more divergent language attitudes as the handover approached by recommending a younger age to start to learn English and an older age to start to learn Putonghua.

Results

As in Study 1 , there were much more fixed theorists $(\underline{N}=148)$ than malleable theorists $(\underline{N}=48$ ) in the sample. A 2 (Implicit Fielief: fixed or malleable) $\times 2$ (Time: wave 1 or wave 2) $\times 2$ (Language: English or l'utonghua) ANOVA, with the last two factors as within-subject factors, was performed on the recommended age of 
language learning. The language main effect was significant, $\underline{F}(1,190)=7.56, p<.01$, $\underline{\mathrm{MS}} \underline{\mathrm{e}}=9.37$. The participants believed that shildren in Hong Kong should start to learn English earlier (mean age $=4.51$ ) than Putonghua (mean age $=5.17$ ).

The predicted three-way interaction was also significant, $\underline{F}(1,190)=7.71, p<.01$, $\underline{M} \underline{\underline{e}}=2.48$. As shown in Figure 5, in September, 1996, fixed theorists believed that children in Hong Kong should start to lea"n English earlier than Putonghua $(\underline{M}=4.30$ for English and 5.11 for Putonghua), $\underline{\mathrm{t}}(146)=-3.07, \mathrm{p}<.001$. However, this difference was greatly attenuated in March, 1997, $\underline{\mathrm{t}}(146)=-1.46$, ns., suggesting that fixed theorists had shifted towards a more assirnilationist attitude.

As for malleable theorists, they belseved in September, 1996 that children in Hong Kong should learn English and Putınghua at about the same age ( $\underline{M}=4.54$ for English and 4.63 for Putonghua), $\mathrm{t}(44)=-.23$, ns. However, in March, 1997, the same malleable theorists recommended children to learn Putonghua $(\underline{M}=6.02)$ much later than English $(\underline{\mathrm{M}}=4.61), \underline{\mathrm{t}}(44)=1.69, \mathrm{p}<.10$, suggesting that malleable theorists had shifted towards a more divergent attitudi al position as the day of the handover approached

In summary, the findings from the present study are consistent with those from Study 1. Over time, fixed theorists hecame more assimilationist in their intergroup language attitudes, whereas malleable theorists became more divergent in their intergroup language attitudes.

\section{Insert Figure 5 here}

Taken collectively, the findings from the two studies suggest that in the course of the political transition, when the decision to assimilate into the more inclusive social category or to maintain a distinctive group membership became more pressing, the implicit beliefs held by Hong Kong people regarding the fixedness or malleability of the social reality were important predictors of how this decision was made. 


\section{General Discussion}

We tested in the present paper an impotant theoretical extension of the social categorization model. On one hand, the social categorization model assumes that social identification serves to fulfill the basic human needs for connectedness and differentiation. On the other hand, social identity is a knowledge structure individuals develop to categorize themselves and their relationships with other people. As such, the social identification processes should also be constrained by the individual's construction of the self and of his or her social environment. We propose that the relative strength of the social motivations served by social identification is constrained by the individual's constructions of the self and of the social reality. We tested this theoretical extension in the context of the advent of the political handover in Hong Kong, which had set up a new agenda for Hong Kong people to negotiate their social identities.

We found, as we predicted, that Hong Kiong people's decision to assimilate into a more inclusive collective or to maintain one's distinctiveness as a Hong Konger was systematically linked to the perceived fixedness or malleability of the social world, particularly when redefining a scial identity became a salient or pressing issue. Although we did not directly test the link between implicit world views and construals of the self, the data are consistent with our proposal that a belief in a fixed social world may set up an expectancy that an individual has to accept the social world as a fixed reality and try to harmonize the self with the unchangeable reality. Such an expectancy mav in turn strengthen the connectedness motivation and drive the individual to seek connectedness with the more inclusive groups. By contrast, a belief in a malleable social world may cohere with a relative agentic view of the self. Within this view, the ndividual is expected to be a selfcontained, highly individuated causal agent, who acts on and changes the social environment. The construction of the self as a $\mathrm{n}$ individuated causal agent may then strengthen the differentiation motivation and drive the individual to seek distinctiveness through identification with distinctive social groups. 
We also found, as we did in our previous research, that in Hong Kong, where an interconnected sense of the self is still frevalent, most people believe that the social reality is relatively normalleable. The relative homogeneity in Hong Kong people s implicit world belief suggests that such a world view may be culturally constructed. Indeed, there is evidence that in Hong Kong, culturally prescribed role expectations are still the primary guides for social action (Chiu \& Hong, 1997).

In short, the present research suggests that social identification is a psychological process whereby individuals construct a social self that could satisfy their fundamental social needs in a way that is coherent with the world views they construct to make sense of the social reality.

\section{Social Identity Theory versus Social Categorization Model}

Aside from the social categorization model, social identity theory is also an important theory of social identification. Within social identity theory (Tajfel, 1974, 1982; Turner, 1981), an individual's beliefs about the malleability of the world and its social institutions also play an important sole in intergroup relations (Bond \& Hewstone, 1988; Bourhis, Giles, \& Tajfel, 1973; Giles \& Johnson, 1981). The theory proposes that members of a group will strive for positive social identities by making social comparisons on valued dimensions This process will lead members of a group to maintain the status quo, assimilate into another group, or set themselves apart from another group (e.g., engage in divergence), depending on (a) the relative status of the two groups, and (b) the subordinate group members' beliefs about the malleability of the society and its institutions. Specifically, members of the subordinate group may accept the status guo as a fixed entity that cannot be changed, or they may believe that it can be changed through concerted group effort (Hogg \& Abrams, 1988). When members of the subordinate group believe that the status quo cannot be changed, one viable alternative for them to acquire positive social identity would be through upward mobility, that is, passing into the dominant group. 
However, when members of the subordinate group believe that the world and its existing social institutions can be changed, they may affirm and positively evaluate their group identity in their interaction with the dominant group, so as to reduce the intergroup status discrepancy (Bord \& Hewstone, 1988; Ethier \& Deaux, 1994; Giles \& Johnson, 1981). Assuming that Chinese Mainlanders as a group enjoy a higher status than do Hong Kong people, the predictions about intergroup relations in transitional Hong Kong generated by social identity theory are similar to those generated by the social categorization model. Specifically, Hong Kong people (assumed to be the subordinate group) may try to pass into the (dominant) Mainlander group when they believe that the social reality cannot be changed, or they may try to distance themselves from the Mainlander group when they believe that the social reality is changeable ${ }^{2}$

However, the evidence for the assumption regarding the relative status of Chinese Mainlanders and Hong Kong people s mixed. In social identity theory, the relative status of a group is positively related to its numerical size, prestige, and control over the channels of the mass media. In addition, status is associated with linguistic vitality; members of the higher status group usually speak a popular, widely respected language that has good representation in public institutions. In a survey of 395 Hong Kong citizens in April, 19.15 (Ho, et al., 1997), 72.6\% of the respondents felt that, compared to mainland China, Hong Kong's political power is very weak. On more objective grounds, Putorghua is an internationally respected language and is used widely in China's national or territorial institutions, whereas Cantonese is a local dialect spoken primarily in the Hong Kong and Guangdong region. Demographic distributions of Putonghua-speakers and Cantonese-speakers are clearly in the favor of Chinese Mainlander: However, the same survey conducted by Ho, et al. (1997) revealed that the majority of Hong Kong respondents (94.9\%) felt that relative to China, Hong Kong's economic power was very strong. Most of them also felt they were superior to Mainland Chinese. Thus, it is 
premature to conclude that Hong Kong pec ple perceived Mainland Chinese to have a higher status than themselves during the ransition period.

On the other hand, by focusing on the basic human motivations underlying social identification, the social categorization model does not require an assumption about the relative status or vitality of the two groups to generate predictions about intergroup relations in transitional Hong Kong. Within the model, social identification is not necessarily politically motivated. Rather, the individual is searching for an identity that would allow him or her to feel optimally connected and differentiated. In this conception, an ir dividual's belief about the malleability of the social reality influences intergroup relations primarily via its association with the construals of the self, i.e., whether the self i: conceived of as a differentiated entity or as an inseparable part of an interdependent social network. Such construals in turn affect the relative strength of the social mot:vations underlying the social identification processes, and ultimately Hong Kong peole's social identities and intergroup relations.

\section{Implications for Intergroup Relations in Post-1997 Hong Kong}

Although it is tempting to associate an assimilationist response with intergroup harmony and a divergent response with intergroup competition, research reveals a more complicated story (e.g., Taylor \& McKirnan, 1984; Wright, Taylor, \& Moghaddam, 1990). An assimilationist response may be associated with recategorization of social groups at a more superordinate level (e.g., "Both Hong Kong Chinese and Mainland Chinese are Chinese"). Such categorization usually promotes identification with superordinate goals, which can in turn facilitate intergroup harmony.

However, Chinese Mainlanders may also want to maintain their group distinctiveness, and may therefore perceive Hong Kong people's assimilation attempts as threats to Mainlanders' distinctive identity. Some powerful members of the Mainlander group may thus respond to Hong Kong people's assimilation attempts by creating new standards for cormparison, which may render group 
assimilation by Hong Kong people difficult (see Giles \& Johnson, 1981). Under such circumstances, Hong Kong people's assimilation attempts may generate intergroup conflicts.

In addition, as Lambert (1979) has noted, individuals who seek assimilation into an inclusive social category may risk losirg the anchoring point for their distinctiveness, which may in turn result in fetlings of anomie and low self-esteem (Hogg, D'Agata, \& Abrams, 1989). Accordingly, Hong Kong people who want to assimilate into the more inclusive Chinese group and expect resistance to assimilation from Chinese Mainlanders may feel that both their connectedness and distinctiveness needs were frustrated. This group of individuals, according to the social categorization model, may experience greater social inefficacy and more negative affect during the political transition.

To test this idea, in a telephone survey of 601 randomly sampled Hong Kong citizens conducted in early 1996, Lau et al. (1996) asked respondents about their attitude towards assimilation. Specifically, the'y were asked whether they would agree to statements such as "After 1997, we will all be Chinese nationals; there is no need to keep the identity of being a Hong Kong person." Based on their responses to these statements, respondents were classified into the Pro-Assimilation group or the Anti-Assimilation group. In addition, expectancy of resistance to assimilation from the Mainlanders was assessed. Specifically, respondents were asked whether they would agree to statements such as "After 1997 Chinese Mainlanders will come up with obstacles to prevent Hong Kong people from assimilating into mainland society." Depending on their responses to these statements, the respondents were classified into either the high or low resistance group. The high resistance group were those who expected obstruction to assim lation from the Mainlanders, whereas the low resistance group were those who did not expect such obstruction.

Finally, the respondents' sense of social and political inefficacy was assessed by items such as "If Hong Kong becomes polit cally and socially volatile after 1997, Hong Kong people can only sit there and be doomed," and "I worry that the past 
efforts and achievements of Hong Kong people will soon be destroyed in an instant." The Pro-Assimilation groups and the Anti-Assimilation groups did not differ very much in social and political inefficacy. However, those who expected resistance to assimilation from the Mainlanders felt much more powerless than those who expected little resistance. The findings suggest that social and political efficacy is not determined by the decision to connect with or to differentiate the self from the more inclusive group. A more important factor to be considered is the expectancy of whether one's need for connectedness may be frustrated by another group's actions. Conclusion

Serge Moscovici (1971) once asserted that "the development of social psychology was directly influenced by concrete social events," and that the society "puts the questions and also suggests what kinds of answers should be given" ( $p$. 24). The present research capitalized on art unprecedented opportunity that the advent of the political handover in Hong Kong in 1997 has offered for uncovering the relationships of an individual's world views and social identification. By emphasizing the constructive aspects of the social identification processes, we hope that the present study will provide some leads to further explore how implicit social and cultural beliefs interact with the basic motivational structure of social identification. We also hope that this analvsis will throw light on how Hong Kong people constructed their identity at this historical moment. 
Social identification in political transition - 23

\section{References}

Bennett, G. K., Bennett, M. G., Clendenen, D. M., Doppelt, J. E., Ricks, Jr. J. H., Seashore, H. G., \& Wesman, A. G. (1965). Acardemic Promise Tests. New York: Psychological Corporation.

Bond, M. H. \& Hewstone, M. (1988). Social identity theory and the perception of intergroup relations in Hong Kong. International Journal of International Relations, 12, 153-170.

Bourhis, R. Y., Giles, H., \& Tajfel, H. (1973). Language as a determinant of Welsh identity. European Journal of Social Psychology, 3, 447-460.

Brewer, M. B. (1991). The social self: On being the same and different at the same time. Personality and Social Psvchology Bulletin, 17, 475-482.

Brewer, M. B. (1993). Social identity, distinctiveness, and in-group homogeneity. Social Cognition, $11,150-164$

Brewer, M. B. (1997). Multiple identities and identity transition: Implications for Hong Kong. Paper presented at the International Conference on the Transition to HKSARPRC. Hong Kong; 7-9 July 1997.

Chiu, C., Dweck, C. S., Tong, Y. Y., \& Fu, H. Y. (in press). Implicit theories and conceptions of morality. Iournal of Personality and Social Psychology.

Chiu, C., \& Hong, Y. (1997). Iustice in Chinese societies: A Chinese perspective. In H. S. R. Kao \& D. Sinha (Eds.), Asian perspectives on psychology (pp.164-184). New Delhi: Sage

Chiu, C., Hong, Y., \& Dweck, C. S. (in press). Lay dispositionism and implicit theories of personality. Iournal of Personality and Social Psychology.

Coopersmith, S, (1967). The antecedents of self-esteem. San Francisco, CA: Freeman.

Cousins, S. D. (1989), Cuiture and self-perception in Japan and the U.S. Lournal of Personality and Social Psychology 56 , 124-131.

Deaux, K. (1993). Reconstructing social identity. Personality and Social Psychology Bulletin, 19, 4-12. 
Dweck, C. S., Chiu, C., \& Hong, Y. (1995). Implicit theories and their role in judgments and reactions: A world from two perspectives. Psychological Inquiry, 6. $267-285$

Dweck, C. S., Hong, Y., \& Chiu, C. (1993). Implicit theories: Elaboration and extension of the model. Personality and Social Psychology Bulletin, 19, 644-656.

Ethier, K. A., \& Deaux, K. (1994). Negotiating social identity when contexts change: Maintaining identification and responding to threat. Lournal of Personality and Social Psychology, 67, 243-251.

Giles, H., \& Johnson, P. (1981). The role of language in ethnic group relations. In J. C. Turner \& H. Giles (Eds.), Intergroup behavior (pp. 199-243). Oxford, England: Blackwell.

Higgins, E. T. (1990). Personality, social psychology, and person-situation relations: Standards and knowledge activation as a common language. In L. A. Pervin (Ed.), Handbook of personality: Theory and research (pp. 301-338). New York: Guilford.

Ho, D. Y. F., Chau, A. W. L., Lam, S. F., Lee, H. C., \& Chiu, C. (1997). Transitional Hong Kong from a psychological perspective: Confidence in the future. Manuscript under review

Hogg, M. A., \& Abrams, D. (1988). Sucial identification: A social psychology of intergroup relations and group processes. New York: Routledge.

Hogg, M. A.. D'Agata, P, \& Abrams, D. (1989). Ethnolinguistic betrayal and speaker evaluations among Italian Australians. Genetic, Social, and General Psychology Monographs, 115 (2), 153-181.

Hong, Y., \& Chiu, C (1995). Social identification in the face of political transition in Hong Kong: The case of 1997 Proceedings of the Countdown to 1997: Hong Kong in the Transition Workshop. Hong Kong: Novermber, 1995.

Hong, Y., Chiu, C., Dweck. C. S., \& Sacks, R. (1997). Impicit theories and evaluative processes in person cognition. Iournal of Experimental Social Psychology, 33, 296-323. 
Kerlinger, F. N. (1984). Liberalism and conservatism: The nature and structure of social attitudes. Hillsdale, NJ: Lawrence Erlbaum.

Krauss, K. M., \& Chiu, C. (in press). Language and social behavior. In D. Gilbert, S. Fiske, \& G. Lindzey (Eds.), Handbouk of social psychology (4th ed.). New York: Guilford.

Lambert, W. E. (1979). Language as a factor in intergroup relations. In H. Giles and R. N. St Clair (Eds.), Language and social psychology (pp.186-192). Oxford: Blackwell.

Lau, I. Y. M., Chiu, C., Chau, A. W. L., H), D. Y. F., Hong, Y., Lam, S. F., \& Lee, H. C. (1996). Social identity, interoroup orientation, and intergroup relations in transitional Hong Kong. Unpublished manus ript. The University of Hong Kong.

Markus, H. R., \& Kitayama, S. (1991). Culture and self: Implications for cognition, emotion, and motivation. Psychological Review, 98 , 224-253.

Miller, J. G. (1984). Culture and the development of everyday social explanation. Iournal of Personality and Social Psychology, 46, 961-978.

Morris, M. W., \& Peng, K. (1994). Culture and cause: American and Chinese attributions for social and physical events. Lournal of Personality and Social Psychology, 67, 949-971.

Moscovici, S. (1971). Society and theory in social psychology. In J. Israel \& H. Tajfel (Eds.), The context of social psychology: A critical assessment (pp. 17-68). London: Academic Press.

Paulhus, D. L. (1984). Two-component models of socially desirable responding. Lournal of Personality and Social Psychology, 46, 598-609.

Rhee, E., Uleman, J. S., L.ee, H. K., \& Roman, R. J. (1995). Spontaneous selfdescriptions and ethric identities in individualistic and collectivistic cultures. Lournal of Personality and Social Psvchology 699, 142-152.

Shweder, R. A., \& Miller, J. G. (1985). The social construction of the person: How is it possible? In K. J. Gergen \& K. Davis (Eds.), The social construction of the person (pp. 41-69). New York: Springer. 
Snyder, M. (1974). The self-monitoring of expressive behavior. Iournal of Personality and Social Psychology, 30, 526-537.

Tajfel, H. (1972). Experiments in a vacuum. In J. Israel \& H. Tajfel (Eds.), The context of social psychology: A critical assessment (pp. 69-119). London: Academic Press.

Tajfel, H. (1974). Social identity and intergroup behavior. Social Science Information, 13, 65-93.

Tajfel, H. (1982). Social identity and intergroup relations. Cambridge, UK: Cambridge University Press

Taylor, D. M., \& McKiman, D. J. (1984). A five stage model of intergroup relations. British Journal of Social Psychology, 23 291-300.

Triandis, H. C. (1989). The self and siscial behavior in differing cultural contexts. Psychological Review, 96, 506-5.0.

Triandis, H. C., Bontempo, R., Villareal, M. J., Asai, M., \& Lucca, N. (1988). Individualism and collectivism: Cross-cultural perspectives on self-ingroup relationships. Iournal of Personality and Social Psychology, 54, 323-338.

Turner, J. C. (1981). The experimental social psychology of intergroup behavior. In J. C. Turner \& H. Giles (Eds.), Intergroup behavior (pp. 66-101). Oxford: Blackwell.

Wright, S. C., Taylor, D. M., \& Moghaddam, F. M. (1990). Responding to membership in a disadvantaged group: From acceptance to collective protest. Iournal of Personality and Social Psycholc , 58, 994-1003.

Young, L., Giles, H., \& Pierson, H. (1986). Sociopolitical change and perceived vitality. International Journal of Intercultu, ral Relations, 10, 459-469. 
Social identification in political transition - 27

\section{Footnotes}

${ }^{1}$ The participants also filled out a battery of other measures designed for a related longitudinal research on entitativity and stereotyping during the political transition in Hong Kong.

${ }^{2}$ Note however that the target of assimilation in this analysis is Mainland Chinese, another regional group, rather than Chinese, which is a more inclusive group encompassing both Hong Kong Chinese and Mainland Chinese. 


\section{Figure Captions}

Figure 1. An extended social categorization model.

Figure 2. Examples of the 1997-related and 1997-unrelated pictures used in Study 1. Figure 3. The moderating effects of implicit world theory: Retributive justice judgments cued by 1997-related or 1997-urrelated pictures (Study 1).

Figure 4. The moderating effects of implicit world theory: Morality judgments by 1997-related or 1997-unrelated pictures (Study 1).

Figure 5. Recommended age for learning English and Putonghua as a function of implicit world theory and time (Study 2). 


\begin{tabular}{lll}
\hline World View & Self Construal & $\begin{array}{c}\text { Chronic Psychosocial } \\
\text { Needs }\end{array}$ \\
\hline Fixed Theory & Interdependent Self & $\begin{array}{c}\text { Need for Connectedness } \\
\text { Chronically Accessible }\end{array}$ \\
\hline Malleable Theory & Independent Self & $\begin{array}{l}\text { Need for Differentiation } \\
\text { Chronically Accessible }\end{array}$ \\
\hline
\end{tabular}




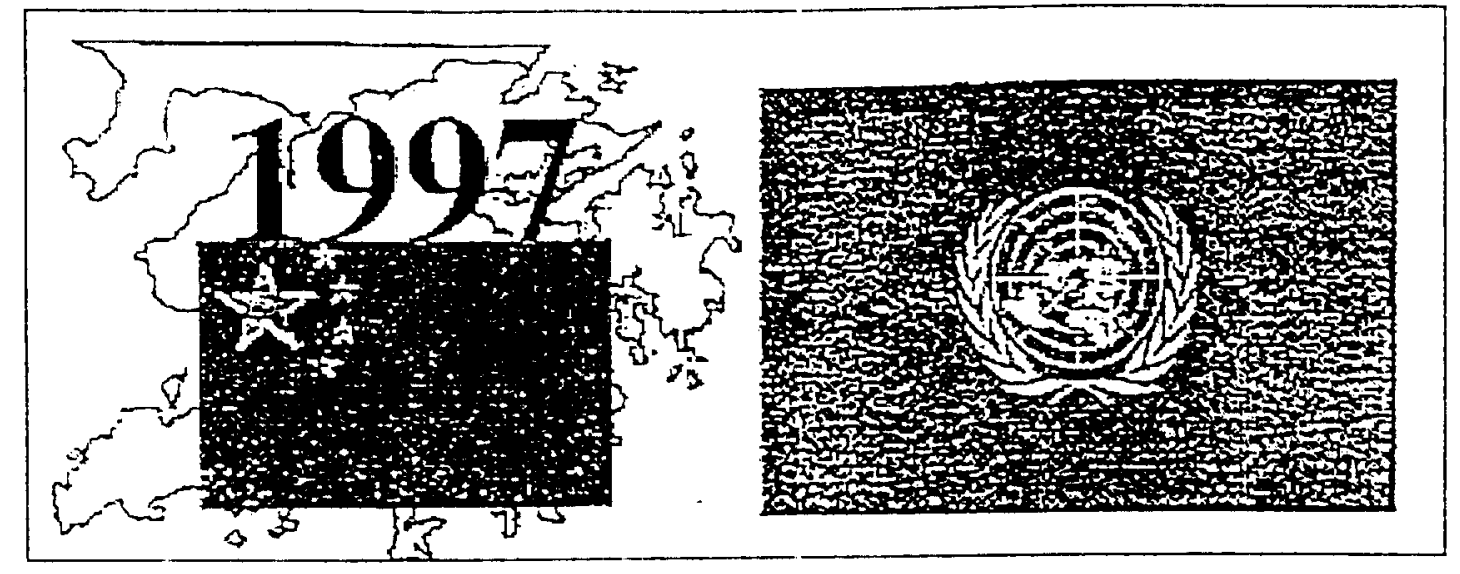




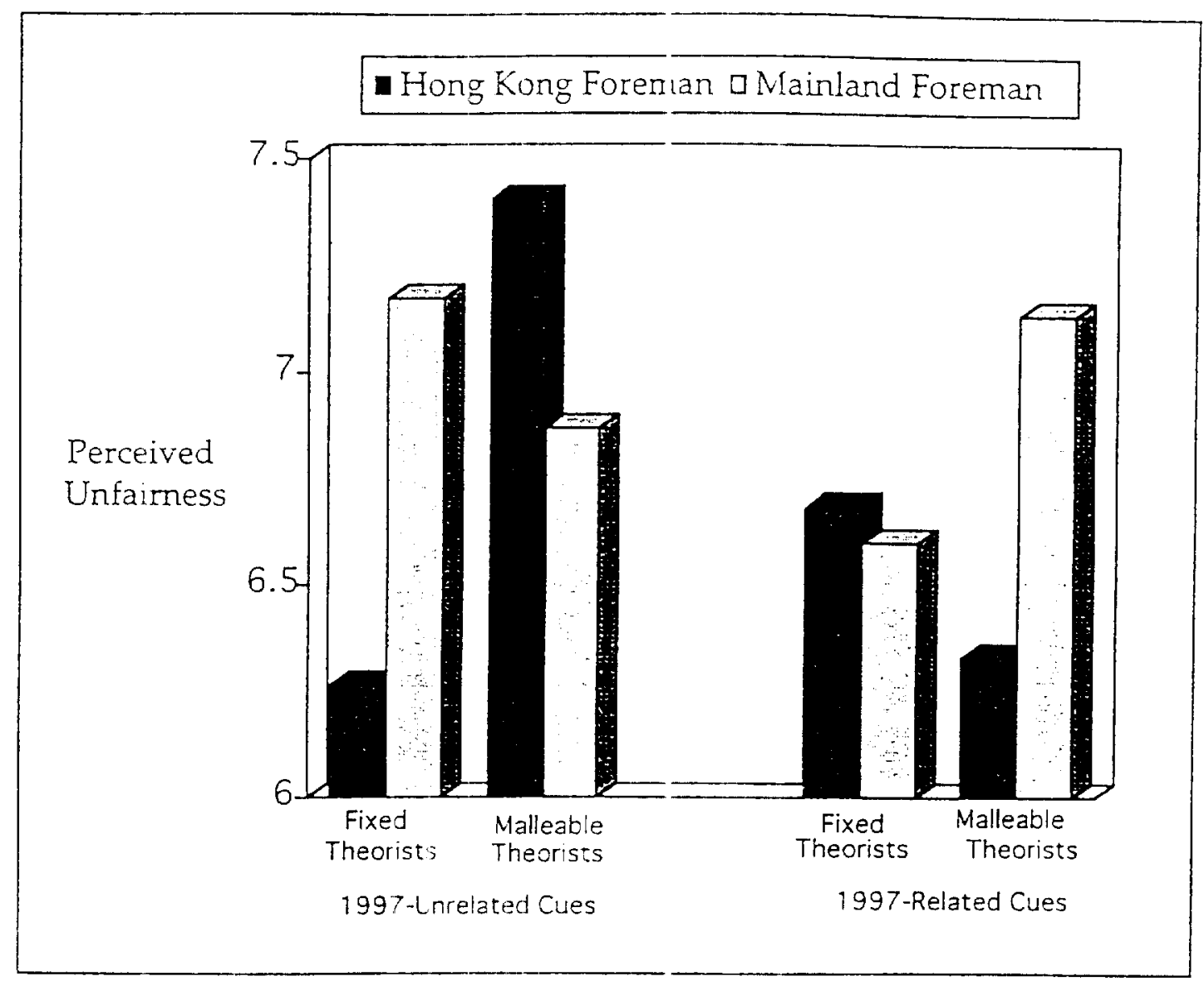




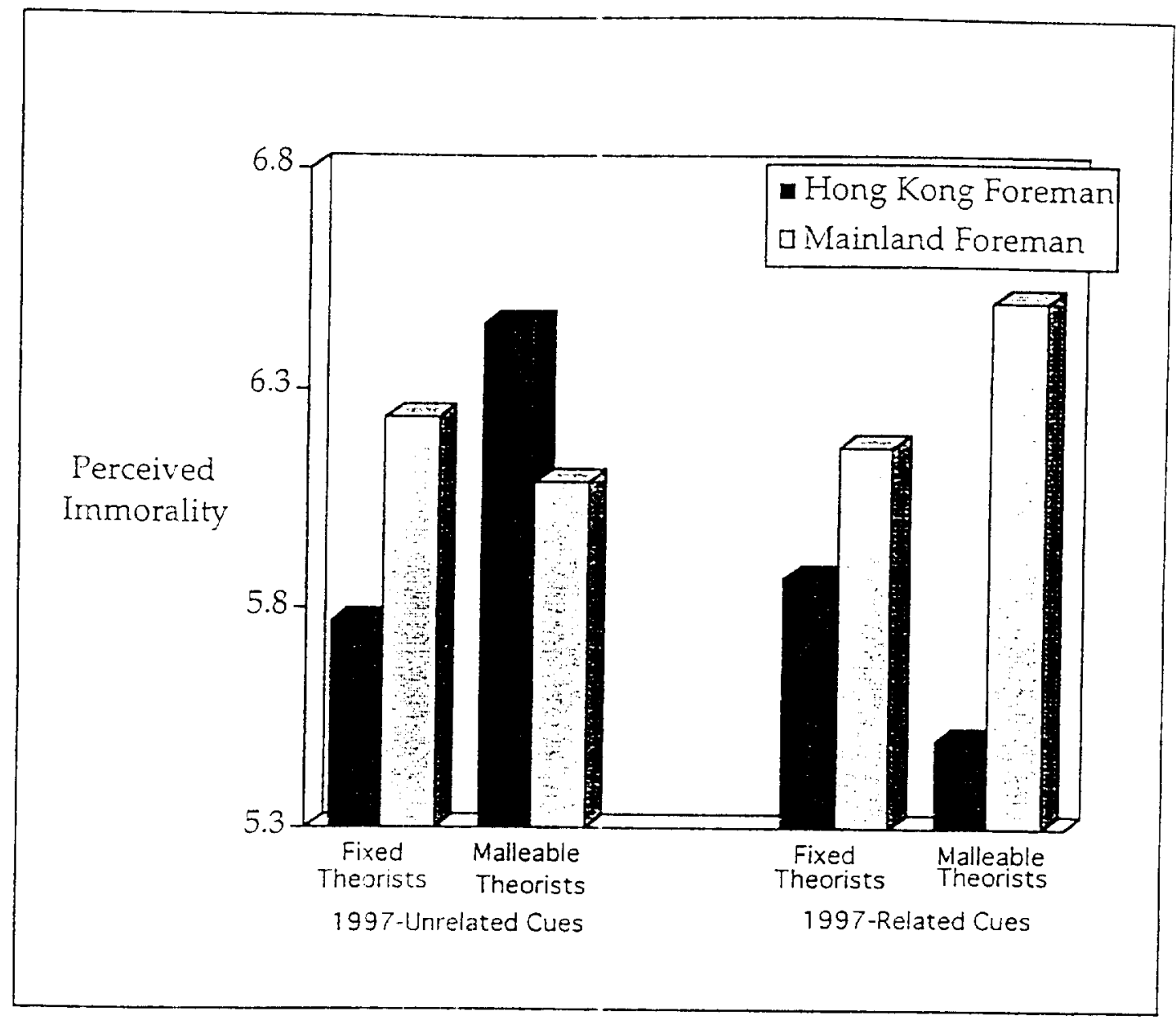




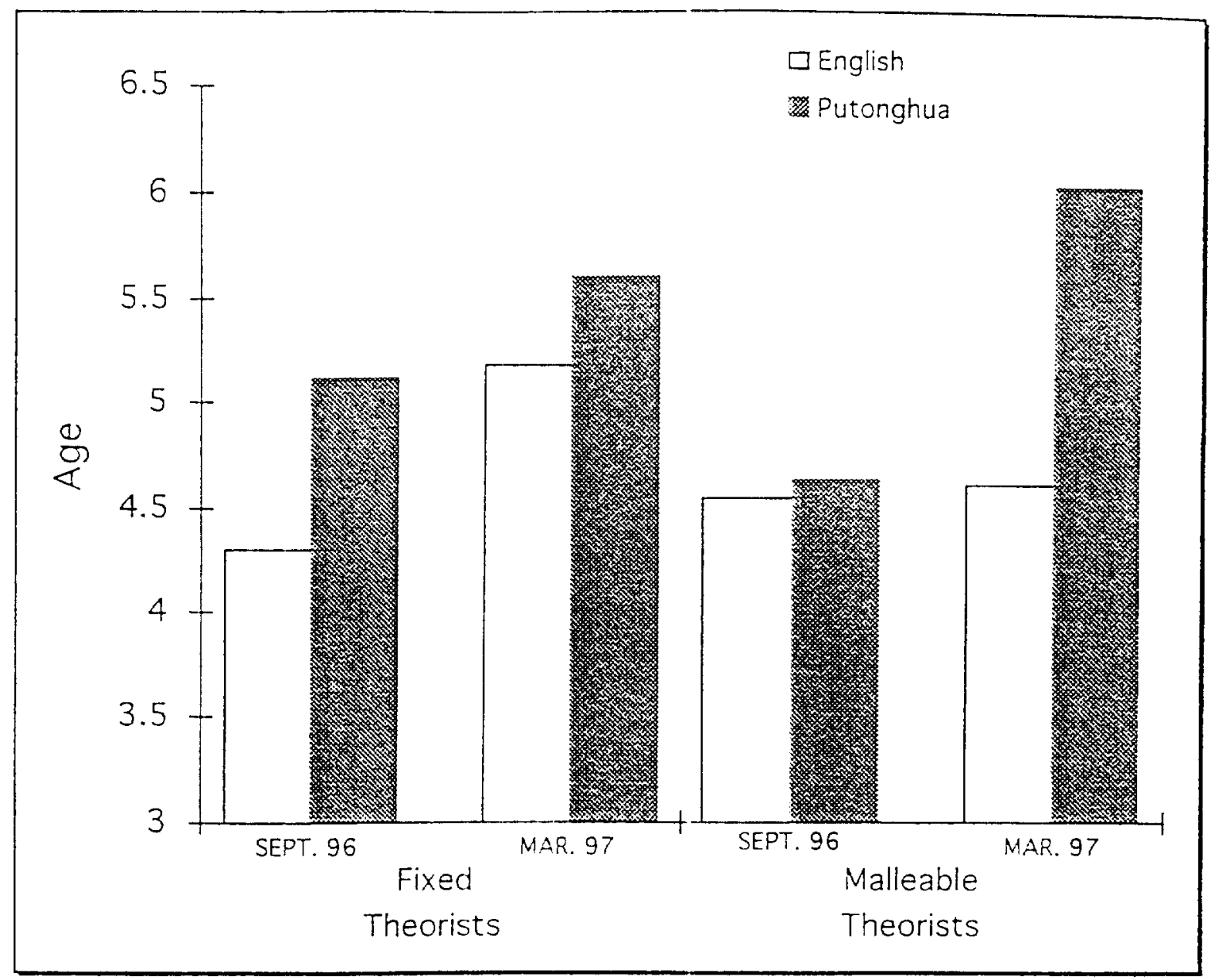

